\title{
UMA ABORDAGEM SOBRE A GESTÃO DE PESSOAS POR COMPETÊNCIA EM
} UMA INSTITUIÇÃO FINANCEIRA

\author{
Bernadeth Mouta Cardozo Colares \\ Graduada em Administração/ISECENSA/RJ \\ bernadeth.c@bol.com.br
}

\section{Sileno Martinho Silva Ribeiro}

Especialista em Gestão Empresarial/ISECENSA/RJ

silenomartinho@hotmail.com

\section{RESUMO}

Este artigo apresenta uma forma de gerir pessoas que está sendo utilizada por grandes organizações, que passam a valorizar cada vez mais o capital humano - suas competências e o quanto estas contribuem para agregar valor à organização. Com o uso de ferramentas inovadoras e eficazes, busca-se promover o crescimento e o desenvolvimento profissional e individual das pessoas, para que as organizações se mantenham atuando em um ambiente de negócios cada vez mais competitivo. É imprescindível que se explore o potencial humano para que as empresas tenham uma atuação mais eficaz em seus devidos mercados, gerando diferenciais entre seus concorrentes. O presente estudo foi feito através de pesquisas bibliográficas, tendo como fontes livros e sites da internet, de onde foram obtidas as informações necessárias para a elaboração desse artigo. Foram levantados dados de uma instituição financeira que utiliza o modelo de Gestão de Pessoas por Competências. Com as respostas obtidas através de um questionário direcionado ao setor de desenvolvimento humano da empresa, foram descritos neste artigo dados com o intuito de mostrar como foi implantado tal modelo de gestão, as etapas que foram utilizadas pela empresa, suas vantagens e seus benefícios.

Palavras-chave: Gestão de Pessoas, Pilares da competência, Gestão por Competências, Instituição Financeira.

\begin{abstract}
This article presents a way of managing people that is being used by large organizations that increasingly give value to the human capital - their competences and how they contribute to add value to the organization. With the use of innovative and effective tools, it seeks to promote the professional and individual growth and development of persons, for organizations to remain working in a business environment more competitive. It is essential to explore the human potential for enterprises to work more effectively in their proper markets, generating differences among its competitors. This study was done through literature searches, as source books and Web sites, regardless of necessary information was obtained for the preparation of this article. Data was collected from a financial institution using the model of Personnel Management Competencies. With responses obtained through a questionnaire directed to the sector's human development company, were described in this article data in order to show how it was implemented this management model, the steps that were used by the company, its advantages and benefits.
\end{abstract}

Keywords: Managing People, Pillars of competence, Competence Management, Financial Institution. 


\section{INTRODUÇÃO}

As organizações são impelidas a passarem em processos de reestruturação, visando adotarem formatos organizacionais mais flexíveis. Os modelos de gestão, especialmente o de gestão de pessoas, vêm acompanhando essa orientação, obrigando os gestores assumirem papéis, cujo foco está mudando para a construção de espaços de trabalho mais democráticos, apoiadores, distributivos de poder e realizadores de objetivos mútuos. Esse contexto também requer a criação de novas estratégias de carreira que exigem compromissos efetivos dos indivíduos com o aprendizado constante, o desenvolvimento de um portfólio de competências e o crescimento profissional.

Inseridas nessa dinâmica organizacional encontram-se as pessoas. São elas, com as suas habilidades e qualidades intrínsecas, as principais responsáveis pela criação das inesgotáveis vantagens que garantem o desenvolvimento e a manutenção de uma empresa. Uma sorte de coisas é esperada do trabalhador contemporâneo, entre elas, qualificação, polivalência, envolvimento com o trabalho, espírito de equipe, e, muitas vezes, abnegação em prol da alavancagem de ganhos de produtividade empresarial.

Essas características que devem ser desenvolvidas para a atuação em novos e exigentes ambientes de trabalho, certamente provocam impactos na saúde, no envolvimento, na satisfação e no desempenho das pessoas no exercício de suas atividades. Reconhece-se, de um lado, que esses novos ambientes proporcionam o surgimento de oportunidades no sentido de valorização de potencial humano e da capacitação para o enfrentamento dos desafios que rotineiramente são apresentadas aos trabalhadores. De outro lado, entretanto, os instrumentos de adequação do homem ao trabalho, como uma decorrência desse processo de transformação ocupacional, tornam-se cada vez mais sofisticados, controlando e alienando o indivíduo por meio de seus mecanismos de dominação. As ambigüidades e os paradoxos, portanto, estão entre os indicadores mais representativos do atual papel que a gestão de pessoas deve desempenhar nas suas ações de conciliar necessidades pessoais e organizacionais.

\section{GESTÃO DE PESSOAS E SUA EVOLUÇÃO}

Com as grandes transformações que estão sempre ocorrendo nos sistemas econômicos, lideradas principalmente pela globalização, as empresas passaram a buscar flexibilidade nas suas operações, com o objetivo de conquistar novas oportunidades, aumentar sua competitividade e gerenciar os riscos e as ameaças aos seus negócios.

As organizações vêm se preparando e inovando suas ações e seus negócios com mais clareza, transformando através de tecnologias e investindo em capital humano para atuar em um mercado mais competitivo. As organizações atuais mostram-se, inexoravelmente, demarcadas por ambientes de trabalho dinâmicos, complexos e desafiadores. Tal panorama vem provocando grandes impactos nos modelos de gestão, nas estratégias de carreira e, especialmente, nos trabalhadores.

Para Chiavenato (2004), as pessoas constituem o principal ativo da organização. A Gestão de Pessoas tem como função permitir a colaboração eficaz das pessoas, para alcançar os objetivos organizacionais e individuais. As pessoas podem aumentar ou reduzir as forças e fraquezas de uma organização dependendo da maneira como elas são tratadas.

$\mathrm{Na}$ gestão de pessoas é encontrada a capacidade e disposição para liderar, desenvolver pessoas e identificar talentos, mediante a análise criteriosa feita através do gestor da organização.

\subsection{O conceito de competência}

Competência tem sido abordada por vários autores como sendo o famoso CHA (conhecimento, habilidades e atitudes/aptidões) das organizações, em que suas principais características são focar o capital humano e agregar valores ao mercado competitivo.

O conhecimento é um indicador de competências que ajuda a lidar com o paradoxo da fortaleza e flexibilidade. Quanto mais conhecimentos colocarmos em nossa bagagem, mais nos tornamos fortes e nos permitimos ser flexíveis para enfrentar as mudanças e as rupturas que surgem em intervalos de tempo. 


\section{PERSPECTIVASCOWine CIÊNCIAS HUMANAS E SOCIAIS APLICADAS}

Habilidade é usar o conhecimento de forma adequada, precisando ser demonstrada na prática, para beneficiar pessoas com seus conhecimentos e informações.

As atitudes agregadas à sua ação cotidiana são os indicadores de impacto e que dá distinção aos profissionais.

Para Fleury (2000), competência é saber ouvir de maneira responsável, implica em mobilizar, integrar, transferir conhecimentos, recursos, habilidades, que agreguem valor econômico à organização e valor social ao indivíduo. Saber agir de maneira responsável significa que o indivíduo deve entregar-se completamente para a empresa, ou seja, comprometer-se com seus objetivos.

\subsection{Ferramentas utilizadas na verificação de competências}

- Entrevistas de mapeamento de competências, em que participam pessoas-chave da empresa. Objetivando traçar perfis desejáveis por funções ou postos de trabalho.

- Entrevistas individuais ou em grupos com os avaliados, para sondagem de potenciais.

- Pesquisa de dados individuais.

- Seminários de verificação de desempenho, em que as equipes passam por situações de teste, participando de atividades que simulam sua realidade.

- Instrumentos específicos de mapeamento de potenciais (questionários, softwares e roteiros).

- Feedback aos avaliados.

- Feedback aos gestores de pessoas, por meio de relatório geral, processado por instrumento que facilite o manuseio pós-implantação.

- Treinamento e orientação para utilização dos dados como ferramenta gerencial de tomada de decisão.

\subsection{Gestão por competências}

O foco principal da gestão por competências está orientado no desenvolvimento das competências, em novos conhecimentos e em fontes por excelência para a conquista de vantagem competitiva sustentável. Este modelo está situado no contexto da economia das organizações e possui o pressuposto de que a posse de recursos raros, valiosos e de difícil imitação confere à organização vantagem competitiva. Tais recursos, por sua vez, são representados, sobretudo pelos conhecimentos e pelas competências das pessoas que trabalham na organização.

Para Carbone (2009) a Gestão por Competências surgiu para responder a questões particulares do cenário empresarial. A emergência desta metodologia de gestão representa uma tentativa de resposta à necessidade de superação da concorrência num mercado globalizado, às exigências por agilidade, diferenciação e inovação contínua, às demandas de aprendizagem e de criação do conhecimento para lidar com as questões inéditas e surpreendentes que surgem a cada dia no contexto organizacional.

Para Rabaglio (2008), a Gestão por Competências garante para a empresa:

- Maior eficácia do Colaborador;

- Maior eficácia Organizacional;

- Maior eficácia na análise das necessidades de treinamento;

- Maior eficácia na gestão de carreira; 
- Maior eficácia dos Gestores e do RH;

- Maior produtividade e aumento de resultados, gerando com esses resultados, benefícios pessoais e profissionais, tais como: maior Produtividade; assertividade; ambiente participativo; ambiente motivacional; comprometimento; gerências fortalecidas; foco nos resultados; e competitividade.

\subsection{Principais ferramentas (subsistemas) da gestão por competências}

\section{1- Mapeamento e mensuração por competências}

- Identifica e organiza as competências técnicas e comportamentais;

- É construído com base nas atividades do cargo;

- Totalmente alinhado com as necessidades do cargo;

- A Mensuração é fornecida pela própria metodologia;

- Não há nenhuma interferência do operador na mensuração de competências;

- Flexibilidade de adaptação para a construção do perfil de cada cargo;

- Fornece o perfil de conhecimentos, habilidades e atitudes necessárias para todas as atividades do cargo.

\section{2- Seleção por competências}

O processo de seleção por competências passou a ser muito utilizado pelos profissionais de recursos humanos. Além das competências técnicas exigidas pelo cargo que implicam conhecimentos e habilidades para cumprimento de determinadas funções, os recrutadores passaram a avaliar também as competências comportamentais, ou seja, as atitudes e os comportamentos conjuminados com as atribuições do cargo. Iniciativa, criatividade, dinamismo, trabalho em equipe, foco em resultados, são alguns exemplos de competências comportamentais.

A elaboração do dimensionamento de pessoas, conhecido como planejamento estratégico de pessoal, é uma atividade fundamental e de grande importância para a orientação dos processos de obtenção de profissionais. Este planejamento define o nível de proficiência esperado para cada competência de cada colaborador, bem como a quantidade de colaboradores na equipe e as necessidades da organização como um todo (PICARELLI, 2002).

\section{3- Avaliação por Competências}

- Possuir ferramentas personalizadas para avaliar cada cargo ou função;

- É construída com base no mapeamento e mensuração dos cargos;

- Avalia as competências necessárias para o cargo;

- É realizada de maneira personalizada e mensurável;

- Identifica os “"gaps” (lacunas) de competências comportamentais de cada colaborador;

- Pode ser implantada no modelo de avaliação de $360^{\circ}$;

- Fornece grande quantidade de relatório para a área de RH; 
- Fornece relatórios de "gaps" (lacunas) de competências para servir de base para o plano de desenvolvimento.

\section{4- Plano de desenvolvimento por Competências}

- Identifica os "gaps" (lacunas) e colabora na realização do plano de desenvolvimento por competências (PDC), através do resultado de avaliação;

- Potencializa o perfil dos colaboradores;

- Fornece à empresa o histórico de desenvolvimento de cada colaborador;

- Realiza a avaliação de eficácia das ações para a garantia do aproveitamento e desenvolvimento;

- Melhora a comunicação entre avaliador e avaliado;

- Ajuda o gestor a desenvolver suas competências de liderança coach;

- Orientação necessária para que o avaliado tenha a oportunidade de investir em seu aperfeiçoamento.

\section{5- Remuneração por Competências}

Nos dias atuais, a lealdade de um colaborador está atrelada a um conjunto de condições diferentes daquelas que eram valor anteriormente. Estabilidade, plano de benefícios abrangente ou possibilidade de trabalhar em uma grande corporação já não atraem tanto os talentos A empresa precisa se conscientizar que a remuneração por competências é uma metodologia mais justa, motivadora, legalmente mais segura e até mesmo mais econômica, o modelo só é verdadeiro se for consistente e bem fundamentado, tendo como principal característica diferenciar os salários das pessoas, fazendo-lhes justiça (RESENDE, 1999).

\subsection{Por que implantar a gestão por competência?}

Gestão por competencias é uma ferramenta que veio para auxiliar as empresas a enxergarem o que elas precisam buscar e treinar em seus colaboradores. Isso independe do tamanho da empresa e de seu alcance no mercado. A gestão por competência tem como objetivo preparar as empresa para obterem sucesso em um mercado totalmente aberto e competitivo.

Com a abertura dos mercados, onde a concorrência se torna mais acirrada, o foco das empresas passa a ser a satisfação do cliente, esse novo comportamento tem um reflexo imediato na relação da empresa com os seus funcionários, pois para atingir seus objetivos é preciso mais que novas tecnologias, tornam-se necessário uma gestão toda voltada para resultados, onde todos são responsáveis para alcançar seus objetivos (CARBONE, 2009).

O que se pode perceber é que a gestão por competência vem agregar formas de avaliação e mensuração dos resultados almejados pelas organizações através da análise e observação dos resultados gerados pelos seus colaboradores e em contrapartida, as empresas remuneram esses funcionários de forma que estimulem o crescimento individual e conseqüentemente da organização.

\section{METODOLOGIA}

A base do presente estudo foi feita através de pesquisa bibliográfica, tendo como fontes livros e sites da internet. Foram levantados dados de uma instituição financeira, através de um questionário com 15 perguntas que podem ser conferidas no final deste artigo relacionadas à implantação do modelo, como foi desenvolvido este modelo de gestão, quais vantagens e benefícios para a organização enviada à área de desenvolvimento humano da empresa, com a finalidade de medir a aceitação do modelo de gestão de pessoas por competência por parte de seus colaborados e da organização. A empresa me enviou as devidas respostas do questionário e o manual do modelo de atuação da Gestão por Competências utilizado pela mesma. 


\section{PERFIL DA EMPRESA PESQUISADA}

A empresa pesquisada é uma instituição financeira brasileira com aproximadamente 80.000 empregados e lucro líquido anual superior a R \$ 2,5 bilhões (projeção para 2010). A empresa possui mais de 2000 pontos de atendimento próprios. Além destes, há áreas de apoio distribuídas por regiões do Brasil e também aquelas vinculadas à sua matriz, de onde saem as diretrizes estratégicas.

Produtos voltados para pessoas físicas, como conta corrente, cheque especial, cartão de créditos e um portfólio de operações de crédito - dentre eles financiamento habitacional, bem como aqueles voltados para pessoas jurídicas - como serviço de cobrança, folha de pagamento, crédito para investimento, capital de giro e antecipação de recebíveis, são alguns exemplos que possibilitam visualizar as muitas operações com as quais seus empregados lidam diariamente.

Considerando o perfil da empresa, pode-se visualizar a necessidade de mapeamento de competências necessárias para o sucesso de seus negócios, o que de fato ocorrerá a partir do efetivo desenvolvimento de pessoas, com foco nas competências esperadas, para assumirem os mais variados postos na organização, que vão desde aqueles de natureza gerencial até aos de caráter técnico e de assessoramento.

\subsection{Dados da pesquisa}

A pesquisa realizada neste trabalho tem como objetivo mostrar a Gestão de Pessoas por Competência, cujo modelo foi adotado em 2000 em alguns setores, com perspectivas de implantação em 2002 para os demais cargos e futuramente para toda a empresa e parceiros estratégicos. Foi enviado um email com um questionário, no dia 01/09/10 ao setor de gestão de pessoas da instituição e obtido resultado bastante inovador e eficaz na empresa pesquisada.

Trata-se de um modelo dinâmico que toma como referência a estratégia da empresa para direcionar as ações de recrutamento e seleção, treinamento e formação, gestão de carreiras, desempenho e estabelecimento de parcerias, mediante a captação, retenção e o desenvolvimento de competências necessárias ao alcance dos objetivos estratégicos.

A empresa adotou este modelo de Gestão de Pessoas por Competências ciente dos desafios das mudanças contextuais, que vêm instigando as empresas a realinharem suas práticas de gestão e suas estratégias para garantir sua participação no mercado futuro. No início de $2000 \mathrm{com}$ o nível estratégico: Superintendentes Nacionais e de Negócios, Gerentes Nacionais e Consultores Técnicos, já apresentava resultados nas formas de planos de desenvolvimento corporativos e no provimento de alguns cargos.

Antes deste modelo de gestão por competências a empresa começou a trabalhar com sistemáticas de avaliação do desempenho, em 1981, com o objetivo de estruturar uma sistemática de promoção por merecimento que permaneceu até 1989, quando foi implantado o primeiro modelo participativo de avaliação do desempenho, cuja referência utilizada para avaliação foi o grupo de trabalho no qual o empregado estava inserido.

De 1992 a 1994, foi adotado um modelo de Avaliação de Desempenho por Resultado, a partir de uma preocupação em vincular o desempenho dos empregados aos resultados da empresa. $\mathrm{O}$ modelo estabelecia o acompanhamento, de forma sistemática, da atuação do empregado na atividade exercida tendo em vista comparar o desempenho apresentado com o que era esperado (resultados desejados). Já em 1998 foi implantada uma Avaliação de Desempenho Gerencial para avaliar os gerentes que trabalhavam nas unidades de negócio com o intuito de subsidiar o remanejamento e a renovação dos gerentes.

Entre 1999 e 2000, foi desenvolvido um Sistema de Avaliação de Desempenho Gerencial, contemplando a avaliação das competências gerenciais básicas necessárias para o alcance dos resultados da organização. Este modelo antecedeu os primeiros estudos para a implantação de um modelo de gestão de pessoas por Competências. As necessidades para a implantação foi a integração com os subsistemas do modelo de gestão de pessoas da empresa, essenciais à consecução dos objetivos organizacionais 
consolidando a idéia de que é de fundamental importância de se direcionar, de forma harmônica, os esforços das pessoas para objetivos estratégicos sem deixar de considerar seus interesses.

Em 2000 teve início a implantação do modelo Gestão de Pessoas por Competências cujo objetivo geral era identificar as ações de desenvolvimento necessárias para potencializar as competências que poderiam contribuir para a concretização das estratégias da organização. No período entre 2003 e 2004, foi efetuado o mapeamento da competência gestão de pessoas, envolvendo todos os ocupantes de cargos gerenciais. Em 2005, foram mapeadas as competências gestão de pessoas, orientação ao cliente e orientação a resultados ainda com os cargos gerenciais. Em 2006, foram avaliadas as competências gestão de pessoas, orientação ao cliente, orientação a resultados e trabalho em equipe entre todos os empregados que ocupavam cargos gerenciais, técnicos e de assessoramento. Até então, o que a empresa denominou mapeamento configurou de fato numa avaliação dos empregados.

\subsection{Os tipos de competências definidos pela empresa}

Competências corporativas, conjunto de qualificações e tecnologias da empresa, necessárias ao alcance dos objetivos estratégicos. Características: são de difícil imitação pelos concorrentes; permitem acesso aos mercados específicos atuais e futuros; são percebidas pelo cliente.

Competências das pessoas, conjunto de conhecimentos, habilidades e atitudes que geram resultados para a organização e agregam valor à pessoa. As competências das pessoas são identificadas a partir das competências corporativas. Por isso, estão relacionadas aos objetivos estratégicos da organização. Características: geram diferencial no desempenho da organização; são mensuráveis, treináveis, observáveis; independem da estrutura da organização

Competências técnicas, conjunto de conhecimentos, habilidades e atitudes aplicados aos processos organizacionais que garantem a manutenção e a alavancagem das atividades com desempenho superior. São identificadas a partir dos processos organizacionais. 
Tabela 1: Vantagens do modelo. Fonte: Manual do Modelo de Atuação da Empresa Pesquisada

\begin{tabular}{|c|c|}
\hline Para a empresa & Para o empregado \\
\hline $\begin{array}{l}\text { - Alinhamento das competências individuais } \\
\text { às estratégias organizacionais. }\end{array}$ & $\begin{array}{l}\text { - Transparência nos critérios de provimento, } \\
\text { seleção, sucessão e gestão de desempenho. }\end{array}$ \\
\hline $\begin{array}{l}\text { - Gestão com foco em resultados e } \\
\text { desenvolvimento. }\end{array}$ & $\begin{array}{l}\text { - Elaboração de planejamento das ações de } \\
\text { desenvolvimento com vistas ao encarreira } \\
\text { mento. }\end{array}$ \\
\hline $\begin{array}{l}\text { - Visão de futuro da empresa traduzida em } \\
\text { ações das pessoas. }\end{array}$ & $\begin{array}{l}\text { - Desenvolvimento de } \begin{array}{l}\text { competências que } \\
\text { agrefissional }\end{array} \\
\text { reconhem valor } \\
\text { reconhento. }\end{array}$ \\
\hline $\begin{array}{l}\text { Eliminação das lacunas entre o que pode fazer } \\
\text { a organização e o que os clientes esperam que } \\
\text { seja realizado. }\end{array}$ & - Construção de seu próprio desenvolvimento. \\
\hline $\begin{array}{l}\text { - Aproveitamento dos talentos existentes na } \\
\text { empresa. }\end{array}$ & $\begin{array}{l}\text { Maior apoio da empresa para } \mathrm{o} \\
\text { autodesenvolvimento. }\end{array}$ \\
\hline $\begin{array}{l}\text { - Preparação do empregado para funções } \\
\text { futuras. }\end{array}$ & $\begin{array}{l}\text { - Preparação do empregado para funções } \\
\text { atuais e futuras. }\end{array}$ \\
\hline
\end{tabular}

\subsection{As competências desenvolvidas na instituição financeira pesquisada}

As estratégias definem tanto as competências da organização quanto as competências das pessoas. É por meio do processo de aprendizagem que se desenvolvem as competências das pessoas e, conseqüentemente, a organização adquire novas competências ou mantém as existentes.
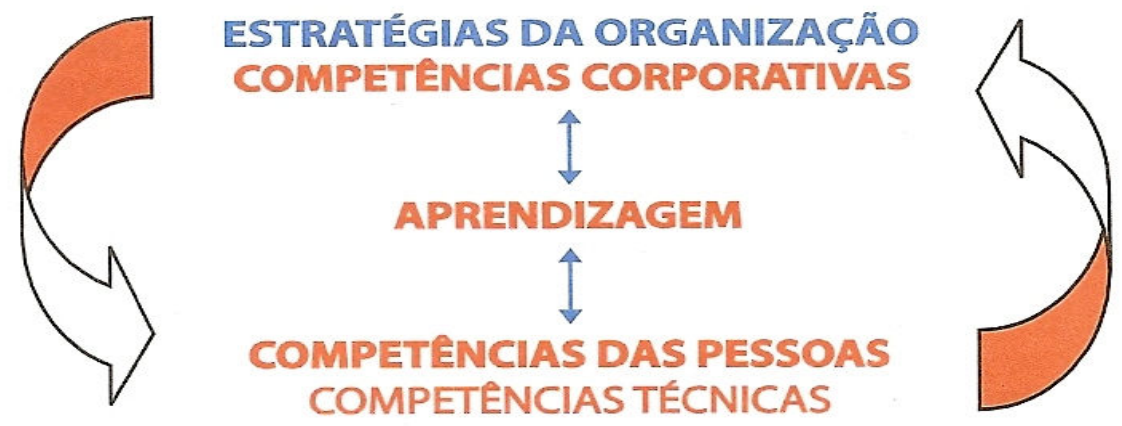

Figura 1: Estratégias da Organização. Fonte: Manual do Modelo de Atuação da empresa pesquisada. 


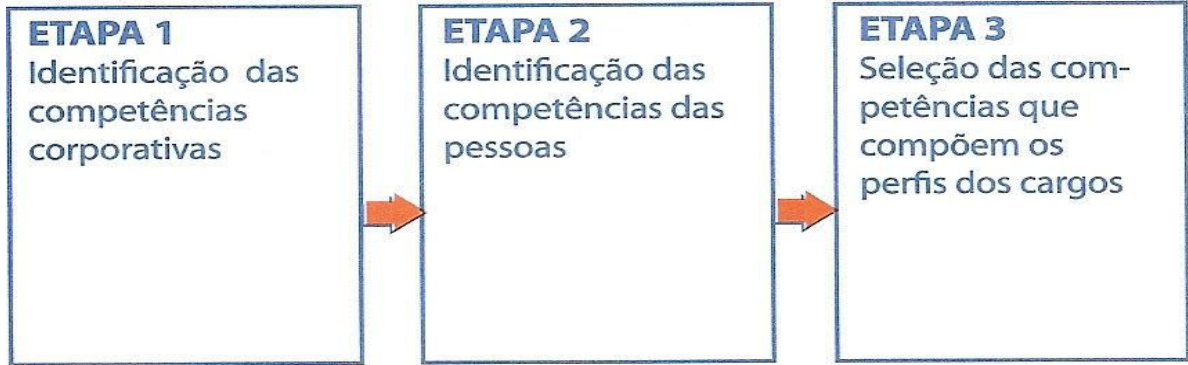

\begin{tabular}{|l|l|l|}
\hline $\begin{array}{l}\text { ETAPA 4 } \\
\text { Mapeamento de } \\
\text { competências }\end{array}$ & $\begin{array}{l}\text { ETAPA 5 } \\
\text { Certificação de } \\
\text { competências }\end{array}$ & $\begin{array}{l}\text { ETAPA 6 } \\
\text { - Planos de Desen- } \\
\text { volvimento Indivi- } \\
\text { dual - PDI e } \\
\text { Corporativo - PDC } \\
\text { - Banco de Compe- } \\
\text { tências }\end{array}$ \\
\hline
\end{tabular}

Figura 2: Etapas do desenvolvimento. Fonte: Manual do Modelo de Atuação da Empresa Pesquisada.

Na etapa 1 a identificação das competências corporativas foram a partir da estratégia da empresa em continuar atuando em três segmentos de negócios: desenvolvimento urbano, transferência de benefícios e serviços financeiros, com foco no cliente, controles e métricas e nivelamento de resultados. Esta etapa constitui na análise das forças, fraquezas, oportunidades e ameaças para a realização dessa estratégia.

As competências corporativas passam a nortear as ações que alavancam a organização a mercados atuais e futuros e agregam valor à sociedade.

\subsection{Competências corporativas identificadas na empresa:}

- Gestão de produtos por segmento;

- Gestão de recursos;

- Gestão das relações;

- Gestão de transferência de benefícios;

- Controle de custos operacionais;

- Venda cruzada;

- Gestão de risco;

- Qualidades de atendimento;

- Gestão de processos;

- Gestão de clientes por segmento;

- Gestão de canais de distribuição;

- Inovação; 
- Gestão de crédito imobiliário;

- Exploração de oportunidades de negócios;

- Sinergia;

- Gestão de saneamento e infra-estrutura urbana;

- Controles e métricas.

Na etapa 2 a identificação das competências das pessoas, foi a partir das competências corporativas. As competências das pessoas constituem-se de comportamentos que permitem a concretização das competências corporativas.

\subsection{Competências das pessoas identificadas na empresa:}

- Orientação ao cliente;

- Orientação estratégica;

- Orientação e resultados;

- Negociação;

- Trabalho em equipe;

- Gestão de clientes;

- Especialização;

- Gestão da mudança;

- Gestão da informação;

- Inovação;

- Gestão de negócios;

- Gestão de pessoas;

- Controle de gestão;

- Gestão social.

$\mathrm{Na}$ etapa 3 entre as 14 competências das pessoas citadas acima, foram selecionadas até 6 para compor os perfis dos cargos. É um conjunto de competências priorizadas para o cargo ou grupo de cargos, no grau mínimo recomendado.

$\mathrm{Na}$ etapa 4 faz a comparação do perfil de competências do grupo de cargos com o perfil de competências do empregado ocupante do cargo. Tem por objetivo subsidiar gestor e empregado a identificar o perfil final do empregado. 
Tabela 2: Tipos de Mapeamento. Fonte: Manual do Modelo de Atuação da Empresa Pesquisada.

\begin{tabular}{|c|c|c|c|}
\hline $\begin{array}{c}\text { Tipo de } \\
\text { mapeamento }\end{array}$ & $\begin{array}{l}\text { Competências objeto } \\
\text { de mapeamento }\end{array}$ & $\begin{array}{l}\text { Quem faz o } \\
\text { mapeamento }\end{array}$ & Quem é mapeado \\
\hline Automapeamento & $\begin{array}{l}\text { Todas do perfil do } \\
\text { grupo de cargos a que } \\
\text { pertence } \\
\text { empregado. }\end{array}$ & $\begin{array}{l}\text { O próprio } \\
\text { empregado. }\end{array}$ & $\begin{array}{l}\text { O próprio } \\
\text { empregado. }\end{array}$ \\
\hline Pelo gestor imediato & $\begin{array}{l}\text { Todas do perfil do } \\
\text { grupo de cargos a que } \\
\text { pertence o empregado } \\
\text { mapeado. }\end{array}$ & O gestor imediato & $\begin{array}{l}\text { O empregado } \\
\text { diretamente } \\
\text { subordinado. }\end{array}$ \\
\hline Pelo subordinado & Gestão de pessoas & $\begin{array}{l}\text { O empregado } \\
\text { diretamente } \\
\text { subordinado }\end{array}$ & O gestor imediato \\
\hline $\begin{array}{l}\text { Por vinculação } \\
\text { técnica }\end{array}$ & $\begin{array}{l}\text { Todas do perfil do } \\
\text { grupo de cargos a que } \\
\text { pertence o empregado } \\
\text { mapeado. }\end{array}$ & $\begin{array}{l}\text {-Gerente nacional de } \\
\text { administração da rede } \\
\text { de venda; } \\
\text { - Superintendente de } \\
\text { negócios; } \\
\text { - Gerente de } \\
\text { segmentos; } \\
\text { - Gerente de } \\
\text { mercado; } \\
\text { - Gerente geral; } \\
\text { - Gerente de } \\
\text { relacionamento; } \\
\text { - Gerente de } \\
\text { atendimento; } \\
\text { - Gerente Júnior. }\end{array}$ & $\begin{array}{l}\text {-Gerente nacional de } \\
\text { administração da rede } \\
\text { de venda; } \\
\text { - Superintendente de } \\
\text { negócios; } \\
\text { - Gerente de } \\
\text { segmentos; } \\
\text { - Gerente de } \\
\text { mercado; } \\
\text { - Gerente geral; } \\
\text { - Gerente de } \\
\text { relacionamento; } \\
\text { - Gerente de } \\
\text { atendimento; } \\
\text { - Gerente Júnior. }\end{array}$ \\
\hline
\end{tabular}

O mapeamento é feito no SIAGE - Sistema de Mapeamento de Competências, que é acessado via intranet.

Na etapa 5 o objetivo é identificar os gaps de competências a fim de direcionar o desenvolvimento do empregado. A certificação também identifica os desempenhos que estão acima do recomendado. Esta é a etapa em que o gestor imediato e o empregado conversam para chegar a um consenso sobre o real perfil de competências do empregado. 
PERSPECTIVASONline CIÊNCIAS HUMANAS ESOCIIIS APLICADAS

Na etapa 6 o PDI (plano de desenvolvimento individual) é o conjunto de ações planejadas de desenvolvimento com os seus indicadores, que revelam a eficácia das ações de desenvolvimento no comportamento de entrega do empregado.

A instituição financeira dispõe de um cardápio de ações educacionais que compõem trilhas de desenvolvimento profissional. Além disso, após a avaliação de competências é repassado o diagnóstico organizacional para a Universidade responsável por essas ações a fim de subsidiar a elaboração de uma ação educacional corporativa.

Utiliza-se atualmente a metodologia de grupos focais envolvendo empregados com a orientação da área gestora do processo, está sendo ampliado o escopo do modelo e retomando um processo que esteve temporariamente suspenso por limitação tecnológica do sistema utilizado para gerenciamento das competências. Esse modelo agrega valor ao empregado, pois permite a construção de plano de desenvolvimento individual, com respectivo apoio e acompanhamento do gestor, e torna transparente a gestão de pessoas, uma vez que a Organização passa a conhecer as competências de todos os seus colaboradores.

\section{CONCLUSÃO}

Podemos concluir afirmando que os objetivos da Gestão por Competências vão desde o aumento dos lucros e dos resultados da empresa, a diminuição dos custos operacionais e o desenvolvimento de uma gestão mais profissionalizada, até o aumento da sintonia da equipe com a empresa e a criação de um ambiente de aprendizagem permanente, de incentivo ao desempenho, à motivação e ao engajamento produtivo. A Gestão por competência aplicadas nas empresas serve para reter principalmente talentos, pois se trata de uma forma de gestão bastante atrativa e justa. Também podemos focar a importância para motivação e clareza de maneira sólida e com certeza há durabilidade de empresa será maior com esse tipo de gestão.

Após a implantação do modelo, a empresa viu seus lucros aumentarem ano a ano. Seus empregados passaram a enxergar regras claras e oportunidades iguais para todos. Sua gestão está mais profissionalizada, inspirando em seus empregados o desejo de se qualificarem cada vez mais visto as oportunidades que lhes são oferecidas.

$\mathrm{Na}$ área comercial, já é reconhecida pela melhora significativa no atendimento, pela capacitação dos empregados - que em muitas situações agem como verdadeiros consultores - e pelos produtos oferecidos, cada vez mais de acordo com as necessidades dos clientes. A empresa está implantando rotinas para diminuir o tempo de atendimento, melhorando seu fluxo, de forma que os clientes que usam os serviços da instituição com menos freqüência e que dependem de atendimento pessoal também tenham uma percepção positiva.

O modelo está consolidado e a empresa vem fazendo as devidas avaliações quanto ao que pode ser melhorado e/ou adaptado.

\section{REFERÊNCIAS BIBLIOGRÁFICAS}

BRANDÃO, Hugo Pena; Guimarães, Tomás de Aquino; Borges-Andrade, Jairo Eduardo. Competências profissionais relevantes à qualidade no atendimento bancário. Revista de Administração Pública, v.35, n. 6, 2001.

BRIGAGÃO, Camila Teles. Gestão por Competências: O papel dos processos de Mapeamento de Competências do Banco do Brasil. Monografia de conclusão de curso de Administração do UNICEUBCentro Universitário de Brasília. 2008. Disponível em: <HTTP://www.scrib.com/doc/6188585/monografiagestao-por-competencias $>$ Acessado em Maio de 2010.

CARBONE, Pedro Paulo - Gestão por competências e Gestão do conhecimento/Hugo Pena Brandão, João Batista Diniz, Rosa Maria de Paula Vilhena. - 3. ed.- Rio de Janeiro. Editora FGV, 2009.

CHIAVENATO, Idalberto. Gestão de Pessoas. $3^{\text {a }}$ edição, Editora elsevier - campus, 2008. 
DUTRA, Joel Souza - Competências - Conceitos e instrumentos para a Gestão de Pessoas na Empresa Moderna. Ed. Atlas S.A. 2004.

GRAMIGNA, Rita Maria - Modelo de Competências e Gestão de Talentos. Ed. Makron Books. São Paulo, 2002.

MANUAL DA EMPRESA PESQUISADA: Guia de Atuação do Modelo, 2002.

RABAGLIO, Maria Odete. Ferramentas de Avaliação de Performace com Foco em Competências.

Qualitymark Editora 2a Ed. 2006.

. Gestão por Competências-Ferramentas para Atração e Captação de Talentos Humanos. Editora Qualitymark-2008.

RESENDE, Ênio. Remuneração e Carreira Baseada em Competências e Habilidades. Qualitymark Editora, 1999.

ZARIFIAN, Philippe. O Modelo da Competência: Trajetória Histórica, Desafios Atuais e Propostas. Editora Senac São Paulo, 2003 